\title{
Comfort and Infection Control of Chitosan-impregnated Cotton Gauze as Wound Dressing
}

\author{
Jefferson M. Souza ${ }^{1}$, Mariana Henriques ${ }^{2}$, Pilar Teixeira ${ }^{2}$, Margarida M. Fernandes ${ }^{3,4}$, \\ Raul Fangueiro ${ }^{5}$, and Andrea Zille ${ }^{5 *}$ \\ ${ }^{1}$ CBMDE, Design and Styling, Federal University of Piauí, Teresina - PI, 64049-550, Brazil \\ ${ }^{2}$ Centre of Biological Engineering, Laboratório de Investigação em Biofilmes Rosário Oliveira, University of Minho, \\ Campus de Gualtar, 4710-057 Braga, Portugal \\ ${ }^{3}$ Centro de Física, Universidade do Minho, Campus de Gualtar, 4710-058 Braga, Portugal \\ ${ }^{4}$ Centre of Biological Engineering, University of Minho, Campus de Gualtar, 4710-057 Braga, Portugal \\ ${ }^{5}$ Centre for Textile Science and Technology, University of Minho, Campus de Azurem, 4800-058 Guimares, Portugal
}

(Received January 16, 2019; Revised February 16, 2019; Accepted February 19, 2019)

\begin{abstract}
The aim of this study was to evaluate the thermo-physiological comfort properties of surgical cotton gauze coated with chitosan $(\mathrm{CH})$ and its effectiveness for the prevention of bacterial colonization. Gauze was coated with $\mathrm{CH}$ at mass fractions of $0.50,0.25,0.125,0.10,0.063 \mathrm{wt} \%$ and the friction, flexibility, thermal, moisture management and mechanical properties were evaluated. The best performing gauze in terms of comfort $(0.125 \mathrm{wt} \%)$ was further evaluated for its ability to inhibit the growth of microorganisms such as bacteria and yeast. Results indicate that the functionalized medical gauze could induce low friction on the wound bed allowing a good degree of moisture and high absorption capacity of wound exudates. Moreover, it shows antimicrobial properties against medical-relevant pathogens. This biofunctional medical gauze demonstrates to deliver an efficient antimicrobial coating and promote the best conditions for maintenance of the wound microenvironment.
\end{abstract}

Keywords: Chitosan, Cellulose, Comfort, Antimicrobial, Wound dressing

\section{Introduction}

A dermal wound is defined as a disruption in the integrity of the skin caused by trauma, abrasion, burns or ulcers, leading to an inadequate performance of its functions. Excessive exudates can impair wound healing and promote bacterial colonization causing difficult-to-treat infections and other complications. Thus, it is vital to restore the skin integrity and function as soon as possible [1]. One of the main roles of intact skin is to act as a barrier for the penetration in the body of the potentially harmful microbial population living on the skin surface. Indeed, when a dermal wound occurs, the skin becomes more susceptible to the colonization of bacteria and fungi [2]. For example immediately after an burn injury, Gram-positive bacteria such as Staphylococcus epidermidis and Staphylococcus aureus may rapidly colonize the wounds [2]. Later, Gramnegative organisms like Pseudomonas aeruginosa or Escherichia coli or fungi species such as Candida albicans may also be implicated [2-4]. The infections caused by these microorganisms may lead to increased mortality, morbidity, length of hospital stay and consequently costs to clinical settings, thus it is extremely important to provide strategies to prevent wound infection and/or promoting a proper wound healing [5]. Therefore, an aseptic, pathogen-free, environment is very important in helping the wound healing process and equally important a proper wound healing

\footnotetext{
*Corresponding author: azille@2c2t.uminho.pt
}

strategies should also include moist management. Maintaining a moist wound environment has been regarded as a key issue in order to facilitate the healing process. The moist environment prevent tissue dehydration and cell death, accelerate angiogenesis, increase the breakdown of dead tissue and fibrin and potentiate the interaction of growth factors with their target cells [6,7]. However, it is also important to note that excessive moisture, e.g. over production of exudate in the wound, may adversely affect healing. It is necessary to provide a moisture balance to obtain an optimal environment for wound healing [8]. Excessive exudate slows down or even prevents cell proliferation, interferes with growth factor availability and contains elevated levels of inflammatory mediators and activated matrix metalloproteinases (MMPs), which impair the healing process [9].

Therefore, the ideal wound dressing material should comprise properties that: i) permits a balanced moisture at the wound site, i.e. being capable of absorb excess of exudates but maintaining certain levels of moist, ii) prevent bacterial infections, iii) do not adhere to the wound bed and iv) to be soft; in order to accelerate wound healing and reduce pain and discomfort [10-12].

Nowadays, many sophisticated dressings made of a wide range of polymeric materials are available to the wound care practitioner. Polymers may be used alone or in combinations thereof, being processed in different dressing designs such as films, foams, fibrous materials, beads, hydrogels, hydrocolloids or even pharmaceutical sprays comprising nano/micro- 
particulate systems [13-15]. Although many of these strategies are considered effective in helping wound healing, they have the main drawback of being highly expensive. There is a tremendous pressure on the medical system to develop costeffective therapies.

One common strategy to obtain inexpensive wound dressing materials is to impart to cotton gauzes added value properties through functionalization with bioactive agents. Cotton gauze is the most commonly used textile for wound management (mainly for cleaning purposes). It is effective in removing blood and exudate from the wound site but promotes dryness and adherence to the wound surface, which cause considerable pain upon removal [16]. Moreover, it can provide suitable media for the growth of microorganisms due to its hydrophilic property retaining moisture, oxygen and nutrient [17]. In order to overcome such drawbacks several works have proven the potential of modified cotton gauze as wound dressings $[16,18,19]$. The application of chitosan, a polysaccharide with homeostatic and antimicrobial properties, onto cotton fabrics has been widely reported to provide wound infection control without losing the inherent textile characteristics of the gauzes [20-23]. However, none of these works provide a comprehensive characterization of functionalized cotton gauzes in terms of their capacity to provide comfort to the patient, apart from its antimicrobial and moisture control properties [24-29].

The goal of this work was to obtain simple, cost-effective added-value chitosan-impregnated cotton gauzes with antimicrobial and comfort properties for wound healing purposes, without losing their inherent textile characteristics. The material was tested against the Gram-positive Staphylococcus aureus (S. aureus), the Gram-negative Escherichia coli (E. coli) and the fungi species Candida albicans (C. albicans). Some essential factors for the development of confortable and efficient wound dressings like thermal properties, water vapour permeability, water uptake, and the amount of vertical wicking, were also determined.

\section{Experimental}

\section{Materials}

Chitosan (DD $85 \%$, ChitoClear hq95-43000, Mw=350 kDa) was purchased from Primex (Iceland) and Gauze Cambric from Alvita $100 \%$ cotton, with a yarns density of 9 warps and 7 weft for $\mathrm{cm}^{2}$. The microorganisms used in this study were the Gram-positive bacterium S. aureus (ATCC 6538), the Gram-negative bacterium E. coli (ATCC 434) and the yeast Candida albicans (C. albicans) SC5314 selected according to the standard JIS L 1902. All the other materials were purchased from Sigma-Aldrich and used without further purification.

\section{Preparation of Chitosan Coating}

$0.50,0.25,0.125,0.10,0.063 \mathrm{~g}$ of chitosan $(\mathrm{CH})$ were dissolved in $100 \mathrm{~m} l$ of distilled water with $1 \%$ of acetic acid. The solutions were stirred at $300 \mathrm{rpm}$ for $30 \mathrm{~min}$ at $70{ }^{\circ} \mathrm{C}$. The heating was kept until the chitosan was completely dissolved. The mixture was stirred until room temperature was reached. The coating $\mathrm{CH}$ solutions were applied to gauze fabrics by a simple dip coating method. Each fabric was dipped in the $\mathrm{CH}$ solution at room temperature for 5 minutes under stirring conditions. The excess coating was then removed by gently rinsing with distilled water and the gauze dried in an oven for 12 hours at $50{ }^{\circ} \mathrm{C}$ [30].

\section{Coated Fabric Weight and Thickness}

The fabric thickness was measured using a digital micrometer (Mitutoyo, Japan) with an accuracy of $0.5 \mathrm{~mm}$. 10 thickness measurements were taken on each test sample at different, randomly chosen points. The mean value was used to infer the average chitosan coating thickness.

\section{FTIR-attenuated Total Reflection Spectroscopy (ATR- FTIR)}

FTIR spectra of cotton gauzes were collected on a FTIR spectrometer (IRAffinity-S1, SHIMADZU, Japan) using a single reflectance ATR cell equipped with a diamond crystal using air at $20{ }^{\circ} \mathrm{C}$ as background. All data were recorded at $20{ }^{\circ} \mathrm{C}$ in the spectral range of $4000-400 \mathrm{~cm}^{-1}$, by accumulating 45 scans with a resolution of $4 \mathrm{~cm}^{-1}$. All measurements were performed in triplicate.

\section{Scanning Electron Microscopic (SEM)}

Morphological analyses of coated chitosan gauzes were carried out with an Ultra-high resolution Field Emission Gun Scanning Electron Microscopy (FEG-SEM), NOVA 200 Nano SEM, FEI Company. Secondary electron images were performed with an acceleration voltage at $5 \mathrm{kV}$. Backscattering Electron Images were realized with an acceleration voltage of $15 \mathrm{kV}$. Samples were covered with a film of Au-Pd (80-20 weight \%) in a high-resolution sputter coater, 208HR Cressington Company, coupled to a MTM-20 Cressington High Resolution Thickness Controller.

\section{Air Permeability}

Air permeability tests of the investigated gauzes were done according to NP EN standard ISO 9237:1997 using a head area of $20 \mathrm{~cm}^{2}$ and differential pressure of $100 \mathrm{~Pa}$. Air permeability is the rate of air passing perpendicularly through a known area under a prescribed air pressure differential between the two surfaces of a material. Air permeability was measured on a FX 3300 air permeability tester by Textest AG, Switzerland at the standard condition of $65 \% \mathrm{RH}$ and $20{ }^{\circ} \mathrm{C}$. Average of 10 readings was taken and the data are reported as mean \pm standard deviation.

\section{Thermal Properties}

Thermal properties (thermal conductivity, thermal resistance 
and heat flux) of gauzes were measured on an Alambeta instrument (Sensora, Czech Republic) and tests performed according to standard ISO EN 31092-1994. The Alambeta simulates the dry human skin and is based on the principle of measurement of heat power passing through the test fabric due to the difference in temperature between the bottom measuring plate $\left(22^{\circ} \mathrm{C}\right)$ and the top measuring head $\left(32{ }^{\circ} \mathrm{C}\right)$. The hot plate comes in contact with the fabric sample at a pressure of $200 \mathrm{~Pa}$. As soon as the plate touches the fabric, the amount of heat power transferred from the hot surface to the cold surface through the fabric is detected and processed to calculate the thermal parameters of fabric. Average of 10 readings was taken for each sample and the data are reported as mean \pm standard deviation.

\section{Water Vapour Permeability}

The water vapour permeability was determined on SDL Shirley Water Vapour Permeability Tester M-261, according to standard BS 7209-1990. As per the British standard the test specimen is sealed over the open mouth of a test dish which contains water and the assembly is placed in a controlled atmosphere of $20{ }^{\circ} \mathrm{C}$ and $65 \%$ relative humidity. Following a period of 1 hour to establish equilibrium of water vapour pressure gradient across the sample, successive weighing of the assembled dish were made and the rate of water vapour permeation through the specimen is determined. All the experiments were replicated 5 times, and the data are reported as mean \pm standard deviation.

\section{Vertical Wicking}

Vertical wicking tests were performed at $20 \pm 2{ }^{\circ} \mathrm{C}$ and $65 \pm 2 \%$ of relative humidity. Specimens of $20 \mathrm{~cm} \times 2.5 \mathrm{~cm}$ cut along the wale-wise and course-wise directions were suspended vertically with its bottom end dipped in a reservoir of distilled water. The bottom end of each specimen was clamped with a $1.2 \mathrm{~g}$ clip to ensure that the bottom end was immersed vertically at a depth of $30 \mathrm{~mm}$ into the water. The wicking heights were measured every minute for $10 \mathrm{~min}$. All the experiments were replicated 5 times, and the data are reported as mean \pm standard deviation.

\section{Water Uptake}

The water uptake of surgical gauze was also monitored during vertical wicking tests. After 10 minutes of gauze $(20 \mathrm{~cm} \times 2.5 \mathrm{~cm})$ immersion the water weight was assessed and compared with the initial water weight $(200 \mathrm{~g})$. All the experiments were replicated 5 times, and the data are reported as mean \pm standard deviation.

\section{Flexibility (Bending)}

FB Kawabata Evaluation System (KES-FB) was used to measure flexibility at $20 \pm 2{ }^{\circ} \mathrm{C}$ and $65 \pm 2 \%$ of relative humidity. The parameters obtained from the hysteresis curves were displayed according to the Kawabata evaluation system for fabric handle. Specimens of $20 \mathrm{~cm} \times 20 \mathrm{~cm}$ were measured in weft and warp directions. All the experiments were replicated 5 times, and the data are reported as mean \pm standard deviation.

\section{Surface Friction}

The surface friction of the surgical gauzes was measured by a FRICTORQ device (University of Minho, Portugal) at the standard condition of $65 \% \mathrm{RH}$ and $20^{\circ} \mathrm{C}$. Frictorq is based on a rotary movement and measurement of the friction reaction torque. The principle is based on an annular shaped upper body rubbing against a flat lower fabric. The fabric sample is forced to rotate around a vertical axis at a constant angular velocity. The coefficient of kinetic friction is then proportional to the torque measured by means of a high precision torque sensor. All the experiments were replicated 5 times, and the data are reported as mean \pm standard deviation.

\section{Antimicrobial Assay}

Antimicrobial characteristics of the samples were evaluated using the standard method for testing antibacterial and antifungal activity and efficacy on textile products according to Standard JIS L 1902:2002. It was used a quantitative method, the absorption method, with the modifications proposed by Pinho et al. (2015). Briefly, inocula of E. coli and $S$. aureus were prepared in $20.0 \pm 0.1 \mathrm{~m} l$ of TSB (Tryptic Soy Broth, Merck) and an inoculum of $C$. albicans was prepared in $20.0 \pm 0.1 \mathrm{~m} l$ of SDB (Sabouraud dextrose broth, Merck) and incubated for a period of 18 to $24 \mathrm{~h}$ at $37 \pm 1{ }^{\circ} \mathrm{C}$ under agitation (120 rpm). Subsequently, microbial concentrations were adjusted to $3 \times 10^{8}$ cells $/ \mathrm{m} l$ via absorbance readings, and based on a corresponding calibration curve. An aliquot of each suspension $(400 \mu l)$ was added to $20 \mathrm{~m} l$ of TSB for $E$. coli and $S$. aures and to $20 \mathrm{~m} l$ of SDB for $C$. albicans, and incubated for $3.0 \mathrm{~h}$ at $37 \pm 1{ }^{\circ} \mathrm{C}$. The microbial concentration was again measured and $3 \times 10^{5}$ cells $/ \mathrm{m} l$ were obtained using a 20 -fold dilution of the respective medium (in distilled water). The specified volume of this inoculum was then added to each sample. Samples were incubated for 18 to $24 \mathrm{~h}$ at $37 \pm 1{ }^{\circ} \mathrm{C}$. Subsequently, $20 \mathrm{~m} l$ of physiological saline solution $(8.5 \mathrm{~g}$ of $\mathrm{NaCl}$ and $2.0 \mathrm{~g}$ of non-ionic surfactant Tween 20 (Sigma Chemical Co.) per litre) were added to the samples, which were then vortexed. The number of living cells was assessed by the serial dilution plate count method. All assays were performed in triplicate and repeated in three independent assays. Following incubation, ratio of microbiostasis was calculated using the formula:

$$
F=M b-M a
$$

When the growth value is more than 1.5 , the test is judged to be effective, and when the growth value is 1.5 or less, the test is judged to be not effective. When the test is not 
effective, a retest is necessary. When the quantitative test has been effective, the bacteriostatic activity value should be calculated in accordance with the following equation:

$$
S=M b-M c
$$

and the bactericidal activity according to:

$$
L=M a-M c
$$

where, $\mathrm{F}$ is the growth value, and $\mathrm{S}$ and $\mathrm{L}$ are the bacteriostatic and bactericidal activity values, respectively. $\mathrm{Ma}$ is the average of common logarithm of number of living bacteria of three test pieces immediately after inoculation of inoculum on standard cloth. $\mathrm{Mb}$ is the average of common logarithm of number of living bacteria of three test pieces after $18 \mathrm{~h}$ incubation on standard cloth. Mc is the average of common logarithm of number of living bacteria of three test pieces after $18 \mathrm{~h}$ incubation on antibacterial treated sample.

\section{Results and Discussion}

The ideal wound dressing should comprise optimal properties such as the ability to create a moist, clean and warm environment, provide hydration if dry, remove the excess of exudate, protect the periwound area, allow gaseous exchange, be impermeable to microorganisms, prevent the release of particles or fibres, reduce pain and discomfort to the patient, be easy to use and finally be cost-effective [10]. Therefore, five different concentrations of chitosan have been impregnated onto cotton gauze and the obtained material was tested for the better conditions in terms of comfort and infection control properties. Chitosan gelling action on contact with exudate reduces dressing adhesion to the wound bed, thus promoting patient comfort and reducing pain at dressing change. In order to estimate the minimal discomfort during application and removal, the analysis of the bending and friction coefficient properties was carried out. The thermo-physiological comfort analysis involves the assessment of the correct thermal and moisture conditions at the surface of the skin in order to provide a confortable feeling. Thus, thermal properties, air and water vapour permeability, vertical wicking and water uptake properties were measured. The best-performing functionalized cotton gauze was further evaluated in terms of capability to provide infection control.

\section{ATR-FTIR}

ATR-FTIR was used to confirm the presence of chitosan in the treated cotton gauze (Figure 1). Only the pure cotton gauze and the gauze coated with the highest concentration of chitosan were analysed. Figure 1(A) shows the dominant absorption peaks at 3330, 2900, 1430 and $1020 \mathrm{~cm}^{-1}$ were respectively attributed to the $v(\mathrm{O}-\mathrm{H}), v \mathrm{~s}(\mathrm{CH} 2), \delta(\mathrm{CH}-\mathrm{O}-\mathrm{H})$ and $v(\mathrm{C}-\mathrm{O})$ of pure cellulose [31]. The intensities of methylene peaks at 2920 and $2850 \mathrm{~cm}^{-1}$ are attributed to the

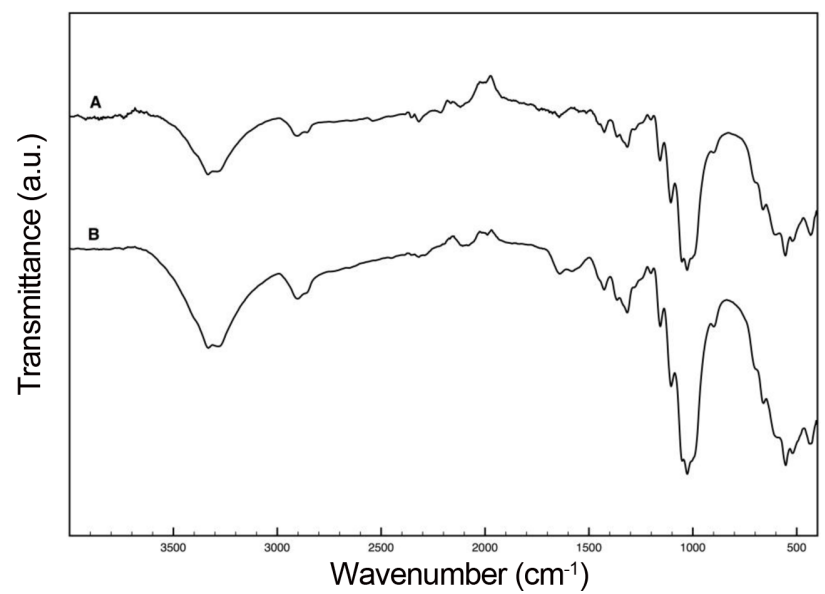

Figure 1. ATR-FTIR spectra of the surgical cotton gauze coated with chitosan; (A) gauze control and (B) gauze coated with $0.5 \mathrm{wt} \%$ of chitosan.

asymmetric and symmetric $\mathrm{CH}_{2}$ stretch and in the case of pure cellulose indicating the amount of waxes remaining on the fabric, but in the case of the coated fabric its increase can be related to the amount of chitosan (Figure 1(B)). The increase of the peaks between $990-1100 \mathrm{~cm}^{-1}$ after chitosan deposition may be attributed to the C-O stretching of free and condensed $\mathrm{C}-\mathrm{OH}$ groups [32]. The intensification of the band at $1640 \mathrm{~cm}^{-1}$ in the chitosan treated gauze can be related to the carbonyl stretching of the secondary amide band (amide I) of the pure chitosan [33]. The band around $1580 \mathrm{~cm}^{-1}$ can be assigned to C-N stretching vibration and refers to the amide group because of the $\mathrm{NH}_{2}$ bending vibration [34]. This last band is therefore not observed in the control cellulose gauze spectra and it can be clearly assigned to the $\mathrm{NH}_{2}$ bending vibration of the amide group of chitosan [34]. The presence of the characteristic peaks of the amide I and amide II, denoting the presence of the acetyl group and confirm that chitosan is partially in the deacetylated form [35]. In this study, the DD of chitosan is $85 \%$. The FTIR results suggest that a strong interaction occurs between the chitosan and cotton gauze [36].

\section{SEM}

SEM micrographs of untreated and chitosan treated $(0.125$ wt\%) cotton gauze samples are shown in Figure 2. Chitosan deposition results in a unique morphological form, having a more smooth and homogenous surface than the unmodified form. It is evident from these micrographs that the formed chitosan coating in the form of slim membranes appears homogeneously on and between cotton fibres surface leading to smoother yarns with a considerable reduction in protruding loose fibres (Figure 2 - bottom line).

\section{Bending Properties}

All chitosan coated cotton gauzes show an increase in 

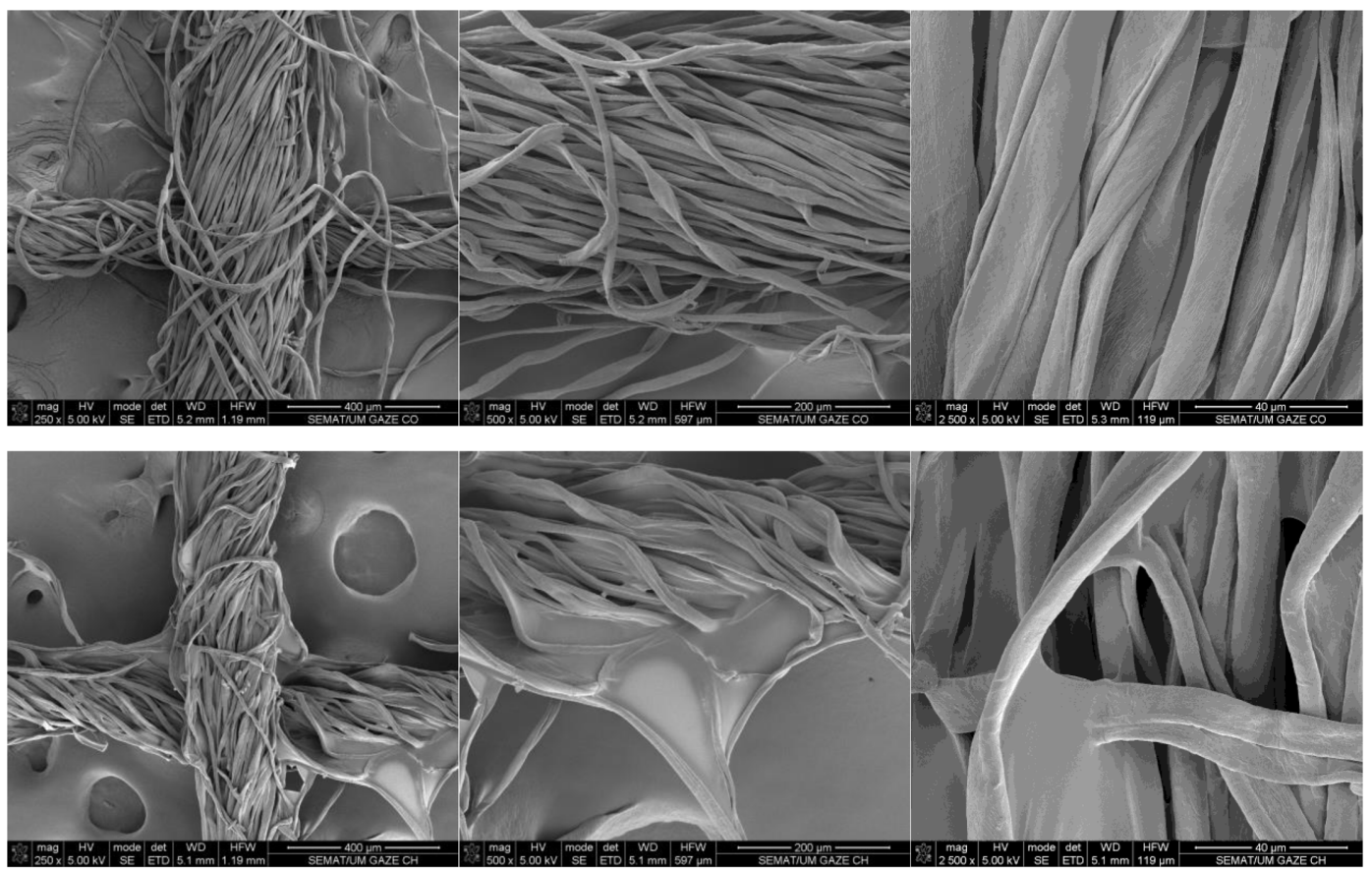

Figure 2. SEM images of surgical gauze control (upper line) and $0.125 \mathrm{wt} \%$ chitosan coated surgical gauze (bottom line) with different magnifications $(250,500$ and $2500 \times)$.

thickness and weight. After chitosan coating, thickness of cotton gauze has increased about $30 \%$ for the Gauze with

Table 1. Weight and thickness of chitosan coated surgical gauzes

\begin{tabular}{ccccc}
\hline Sample & $\begin{array}{c}\text { Weight } \\
\left(\mathrm{g} / \mathrm{m}^{2}\right)\end{array}$ & $\begin{array}{c}\text { Increase } \\
(\%)\end{array}$ & $\begin{array}{c}\text { Thickness } \\
(\mathrm{mm})\end{array}$ & $\begin{array}{c}\text { Increase } \\
(\%)\end{array}$ \\
\hline Control & $24.4 \pm 0.1$ & - & $0.30 \pm 0.03$ & - \\
CH 0.063 & $24.8 \pm 0.1$ & 1.5 & $0.35 \pm 0.02$ & 14.3 \\
CH 0.100 & $25.0 \pm 0.1$ & 2.5 & $0.36 \pm 0.02$ & 16.7 \\
CH 0.125 & $25.1 \pm 0.1$ & 2.7 & $0.37 \pm 0.03$ & 18.9 \\
CH 0.250 & $25.3 \pm 0.1$ & 4.5 & $0.40 \pm 0.03$ & 25.0 \\
CH 0.500 & $25.7 \pm 0.1$ & 5.1 & $0.43 \pm 0.03$ & 30.2 \\
\hline
\end{tabular}

Data represent mean values \pm S.D. $(n=3)$. the higher amount of chitosan ( $\mathrm{CH} 0.500)$ and $14 \%$ for the gauze with the lower one (CH0.063). At the same time, cotton gauze weight had increased about $5 \%$ for Gauze CH0.500 and $1.5 \%$ for Gauze CH0.063 (Table 1). The increase in thickness and weight are directly related with bending stiffness of a fabric that is an important mechanical property that influences its handle, formability and ultimately the comfort properties in a number of medical applications [37]. Fabric flexibility and ability to recover after bending were extrapolated by measuring bending rigidity and bending hysteresis. Table 2 represents the changes of bending rigidity coefficient and bending moment at different chitosan concentrations (from 0 to $0.5 \mathrm{wt} \%$ ) in warp and weft directions. Linear dependencies between bending rigidity $\mathrm{B}$ and concentration of chitosan were observed in all

Table 2. Bending rigidity (B) and bending moment (2HB) in warp and weft directions of the chitosan coated gauzes

\begin{tabular}{crrrrr}
\hline \multirow{2}{*}{ Sample } & \multicolumn{3}{c}{ Warp } & & \multicolumn{2}{c}{ Weft } \\
\cline { 2 - 3 } \cline { 5 - 6 } & $\mathrm{B}\left(\mathrm{gf} \mathrm{cm}^{2} \mathrm{~cm}^{-1}\right)$ & $2 \mathrm{HB}(\mathrm{Nm} / \mathrm{m})$ & & $\mathrm{B}\left(\mathrm{gf} \mathrm{cm}^{2} \mathrm{~cm}^{-1}\right)$ & $0.008 \pm 0.007$ \\
Control & $0.007 \pm 0.001$ & $0.009 \pm 0.002$ & & $0.012 \pm 0.003$ & $0.007 \pm 0.004$ \\
CH 0.063 & $0.013 \pm 0.005$ & $0.010 \pm 0.003$ & & $0.016 \pm 0.002$ & $0.014 \pm 0.001$ \\
CH 0.100 & $0.022 \pm 0.001$ & $0.021 \pm 0.003$ & & $0.0283 \pm 0.006$ & $0.0280 \pm 0.009$ \\
CH 0.125 & $0.0224 \pm 0.009$ & $0.0228 \pm 0.007$ & & $0.063 \pm 0.009$ & $0.067 \pm 0.010$ \\
CH 0.250 & $0.068 \pm 0.018$ & $0.067 \pm 0.017$ & & $0.074 \pm 0.010$ & $0.099 \pm 0.029$ \\
CH 0.500 & $0.183 \pm 0.040$ & $0.174 \pm 0.046$ & & & \\
\hline
\end{tabular}

Data represent mean values \pm S.D. $(n=5)$. 
tested directions. The coated chitosan gauze with the lowest values of bending is the $\mathrm{CH} 0.063$. Its warp bending rigidity increased $32 \%$ and its weft bending rigidity increased $27 \%$ compared to control gauze. The other coated chitosan gauzes are expected to impact negatively upon conformability of a wound. The used bending tester was the KES-FB of the Kawabata Evaluation System. KES-FB apparatus is a standard tool for a thorough evaluation of textile fabric's deformability allowing characterization of fabric's behaviour under low loads and reliability of the results. Standard parameters obtained by KES-FB method were the bending rigidity (B) per unit width in $\mathrm{Nm}^{2} \mathrm{~m}^{-1}$, that is calculated as the mean bending stiffness of two slopes and the bending hysteresis (2HB) value in $\mathrm{Nm} \mathrm{m}^{-1}$ that is obtained by reading the hysteresis width at curvature \pm 1 . Bending rigidity represents the resistance of fabric against flexion and bending hysteresis can be considered as a measure of fabrics ability to recover [38]. In one hand, the increase in bending rigidity in the warp direction is higher than in the weft direction due to the different yarn linear densities used for the fabric assembly. On the other hand, bending hysteresis values in weft direction are 1.7 times lower than in warp direction. The observed increase of hysteresis values (lower bending recovery) in the highly dense chitosan-treated yarns in warp direction is due to the higher resulting inter-fibre friction [39].

\section{Surface Friction}

Chitosan coating does not only provide special functionalities to the cotton gauze, it also imparts stiff and rough feelings difficulting its handle or use. The surface of a textile fabric is not uniformly flat and smooth and traditional cotton gauze adherence of the dressing to the wound often cause frictional trauma on removal resulting in hypertrophic scarring [40]. A low values of coefficient of kinetic friction can be used as acceptable indicator of a smooth fabric surface even if alone it can be insufficient for surface characterization [41]. In Figure 3 it is clear that the coefficient of kinetic friction decreases with the increase in chitosan concentration. The result shows a decrease of $24 \%$ in the cotton gauze coated

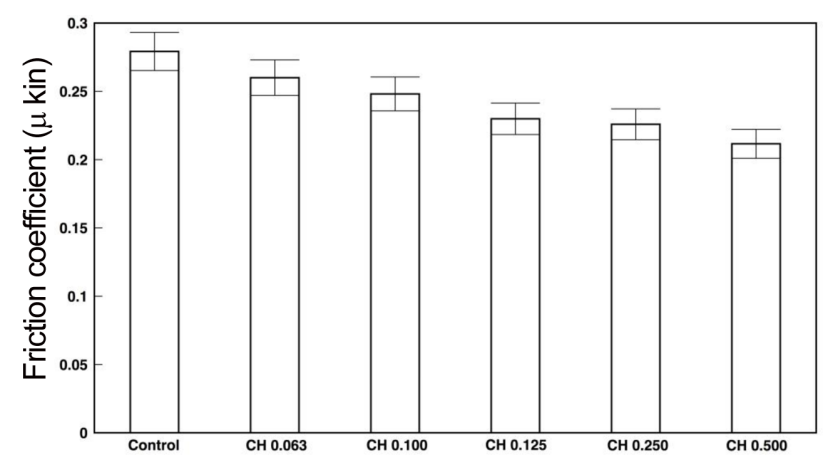

Figure 3. Coefficient of kinetic friction of the chitosan coated gauzes. Data represent mean values \pm S.D. $(n=5)$. with $0.5 \mathrm{wt} \%$ of chitosan in relation to control gauze. The presence of chitosan seems to significantly reduce friction potentially avoiding the risk of epidermal damage, upper dermal skin layers or sheet burns.

\section{Thermal Properties}

The heat transfer through a textile fabric is a complex process involving heat conduction, radiation and convection through and within air, fibres and fabric. However, it is proved that the heat transfer in a textile fabric is mainly dependent on thermal conduction and in minor part (20\%) to radiation [42]. The property used to measure this transfer is thermal conductivity that is defined as the measure of heat flux heat (energy per unit area per unit time) passing though a unit thickness under a unit of heat difference. Thermal
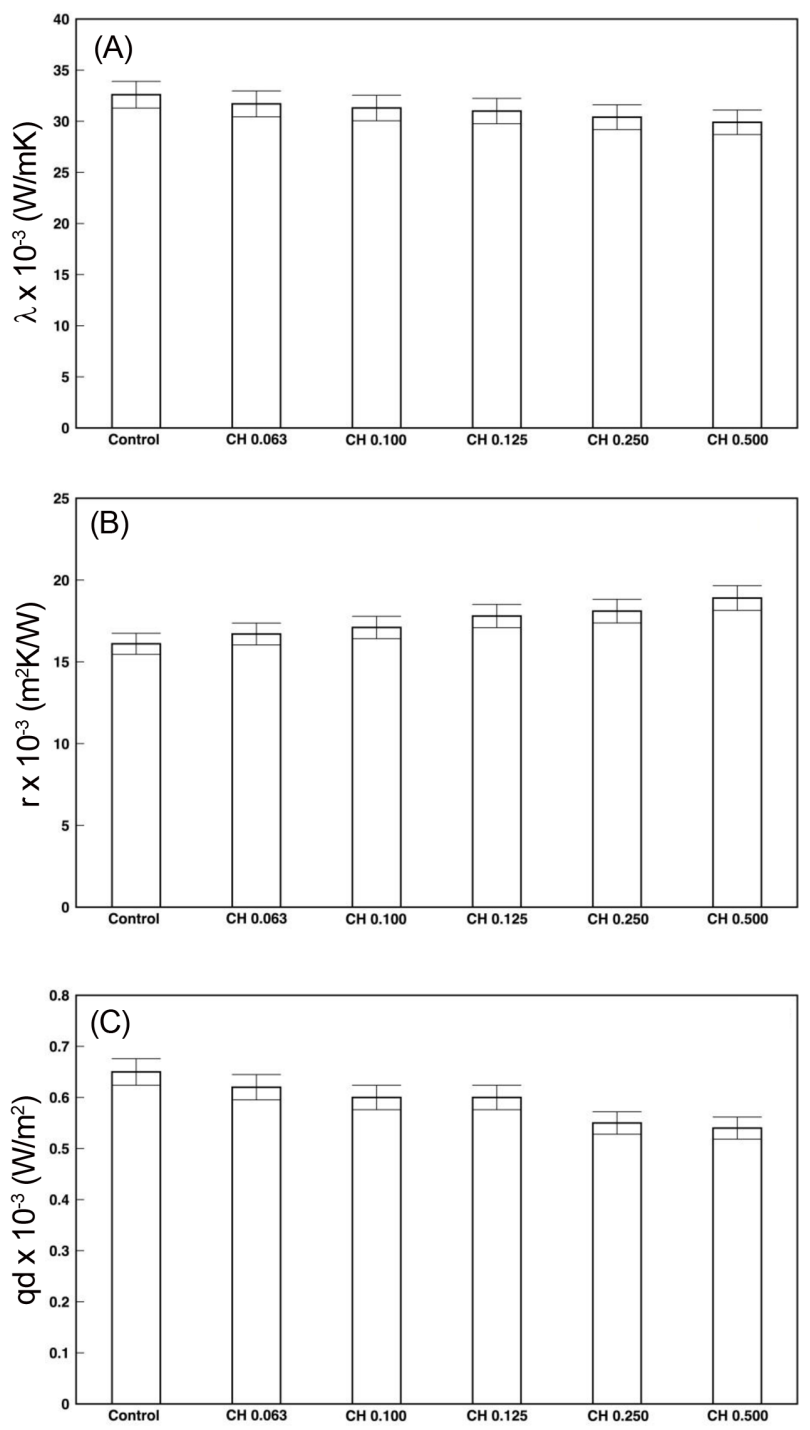

Figure 4. Thermal properties of the chitosan coated gauzes; (A) thermal conductivity, (B) thermal resistance, and (C) heat flux. Data represent mean values \pm S.D. $(n=10)$. 
conductivity is directly proportional to the heat flux, thus, the more increase thermal conductivity, the more increase heat flux [43]. On the other hand, thermal resistance is inversely proportional to thermal conductivity. It represents the temperature difference across a unit area and unit of thickness when a unit of heat flux pass trough the fabric in a unit of time. Thermal resistance can be used to quantitatively evaluate the capacity of a fabric in providing an efficient thermal barrier or in other words, to express the thermal insulation ability of a fabric.

All the chitosan-coated gauzes display lower thermal conductivity (Figure 4(A)) and higher thermal resistance (Figure 4(B)) values than the control gauze due to the enhanced fabric weight and thickness. The gauze with $0.5 \mathrm{wt} \%$ of chitosan shows the best results displaying the lowest thermal conductivity and the higher thermal resistance due to the larger thickness and the greater amount of air entrapped in the structure of the fabric. Thus, it seems that $0.5 \mathrm{wt} \%$ chitosan coated gauze is able maintain a degree of thermal insulation to provide optimum temperature for cell proliferation. The presence of chitosan reduces the heat flow indicating a relatively warm feeling when it touches human skin (Figure 4(C)). Thermal insulation keeps the wound surface warm improving the blood flow to the wound bed and enhancing epidermal migration [44]. In dry fabrics, such as the evaluated gauzes, thermal insulation depends essentially on fabric thickness and, to a lesser extent, on fabric construction and fibre conductivity [45].

\section{Air Permeability}

Air permeability is one of the most important parameters for wound dressings. It is defined as the volume of air which is passed in a certain period of time through a known area of the fabric at a defined pressure difference between the two surfaces of the fabric [46]. A medical dressing must be permeable for gases in order to prevent maceration and gives comfort to the patients, but an excessive air permeability could dry out the wound and have a negative effect on healing [47]. In fibre-based dressings air permeability is mainly affected by the porosity since, for obvious reasons,

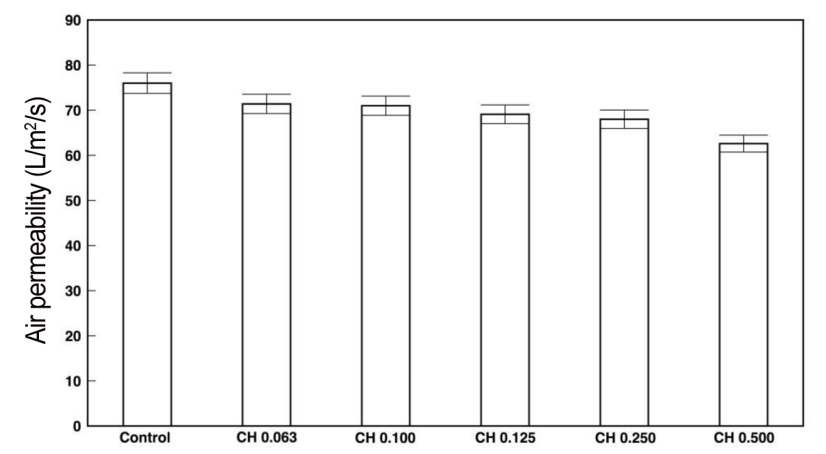

Figure 5. Air permeability values of the chitosan-coated gauzes. Data represent mean values \pm S.D. $(n=10)$. the passage of air through a fabric can only take place in the spaces among fibres and yarns [48]. In Figure 5 are represented the values of air permeability of the gauzes coated with different concentrations of chitosan. Air permeability decreases with the increase in chitosan concentration denoting considerable changes in the porosity of the cotton gauze after chitosan addition. Control gauze shows the highest air permeability being unable to maintain a reasonable moist wound environment. After chitosan coating, the spaces between warp and weft directions are partially filled with chitosan, resulting in a decrease of the inter-fibre distance and the quantity of channels. Based on exposed results, only the concentrations of chitosan 0.125 , 0.250 and $0.5 \mathrm{wt} \%$ have satisfactory air permeability to ensure and maintain optimal wound healing conditions.

\section{Water Vapour Permeability}

Water vapour permeability measures the capability to diffuse perspiration or wound exudate in form of moisture vapour through a fabric. In a dressing the best comfort condition depends mainly to the amount of moisture vapour a fibre is able to transport and not to the amount of water that is absorbed by the fibre [49]. The ideal dressing should be able to control the evaporative water permeability rate in order to maintain a balanced moisture environment thus promoting comfort and healing process without causing maceration [50]. Specifically, a wound dressing must be enough permeable to ensure that moist exudates under dressing are maintained and at the same time inhibit an excess fluid absorption and evaporation that could lead to desiccation of the wound bed [51]. In Figure 6 can be clearly observed that water vapour permeability slightly decreases after chitosan addition but at least a concentration of $0.125 \mathrm{wt} \%$ of chitosan is necessary to have an observable effect.

It is known that fabric air permeability and water vapour permeability are not correlated properties [52,53]. Moreover, in fabrics made of a single type of yarn the water vapour transmission rate do not usually depends on fibre-related factors, such as cross-sectional shape and moisture absorbing

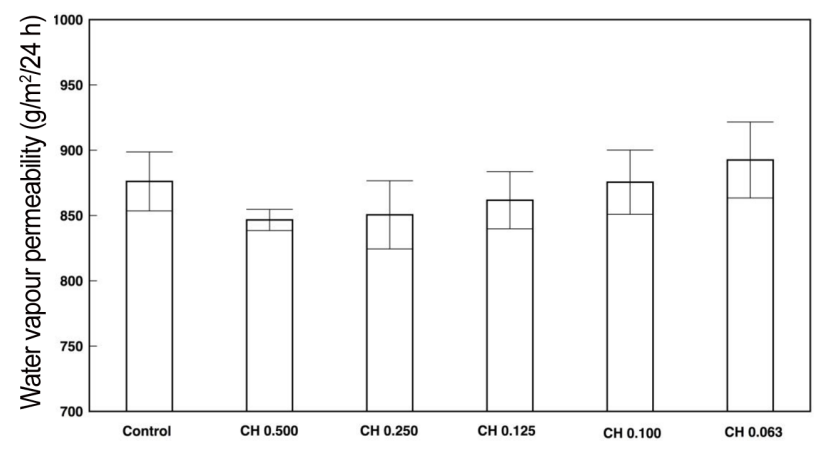

Figure 6. Water vapour permeability after 24 hours of the chitosan coated gauzes. Data represent mean values \pm S.D. $(n=5)$. 
properties but is primarily a function of fabric bulk density. In fact, in this low-density gauze, increased thickness and weight seems to be significantly correlated to water vapour permeability which is in turn strongly affected by the macroporous structure of fabric [54]. The addition of chitosan to cotton causes strong intermolecular hydrogen interactions between the similar polysaccharidic structures of the two polymers resulting in a decrease of the inter-fibre distance and accessibility of the hydrophilic groups, reducing the water vapour transmission rate $[55,56]$.

\section{Vertical Wicking}

Liquid moisture transportation on a fabric is due to a wetting process followed by wicking. Wetting is the initial process of fluid spreading where the fibre-liquid interface replaces fibre-air interface. Wicking is the flow of a liquid through the porous media characterized by the fibre-liquid molecular attraction at the surface. Surface tension, effective capillary pathways and pore distribution are the main variables responsible for the wicking ability in a textile fabric [57]. Hygroscopic dressings based in natural fibres such as cotton are characterised by high liquid moisture transportation and absorption in order to allow the remove of excess exudate from the wound. An efficient level of absorption prevents lateral wicking that can cause maceration at
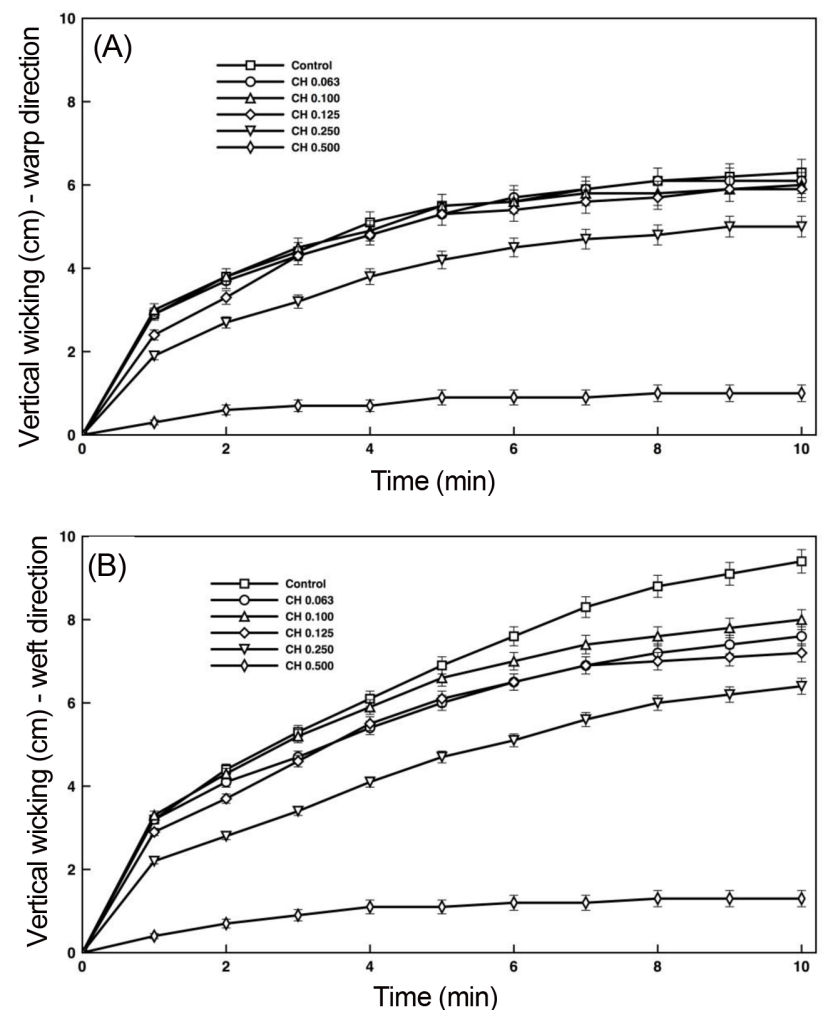

Figure 7. Vertical wicking values in (A) warp and (B) weft directions of the chitosan coated gauzes. Data represent mean values \pm S.D. $(n=5)$. the edge of the wound and maintains a reasonable degree of moist for wound healing [58]. However, wetting have to be controlled since can cause the fabric to swell, changing the geometry among capillary space positions, increasing the weight of the dressing and ultimately affecting the vertical wicking ability. In Figure 7 are shown the vertical wicking heights of the coated gauzes after ten minutes in warp and weft directions. The gauze coated with $0.5 \mathrm{wt} \%$ of chitosan showed the lowest wicking heights $(\sim 1 \mathrm{~cm})$. All the other samples display better wickability and higher absorption in weft direction as compared to warp direction. This is because in this gauze the weft yarn diameter is larger than the warp one. In warp direction only the 0.25 and $0.5 \mathrm{wt} \%$ chitosan concentrations show different wicking height compared to the control gauze (Figure 7(A)). On the other hand, in weft direction all the chitosan concentrations display a lower wicking height than control gauze (Figure 7(B)).

Overall, the presence of chitosan greatly improves the dressing ability to retain liquid, as the fluid is entrapped within its structure. The polymer blocks the water molecules movement maintaining for a longer time a moist environment for wound healing. Since, cotton gauze wickability decrease by increasing chitosan concentration, it is important to found an ideal chitosan concentration in order to maintain a moist environment and at the same time avoid maceration [59].

\section{Water Uptake}

One of the most important function of a wound dressing is its ability to absorb fluid from a highly exuding wound maintaining a moist environment in a dry wound [60]. It is clear that high chitosan concentrations significantly reduce the absorptive capacity of cotton gauze. This effect is due to the reduction in porosity and availability of hydrophilic groups due to the hydrogen bond interactions between cellulose and chitosan. The higher water uptake at moderate concentration of chitosan could be attributed to the high hydrophilicity of both cellulose and chitosan polymers

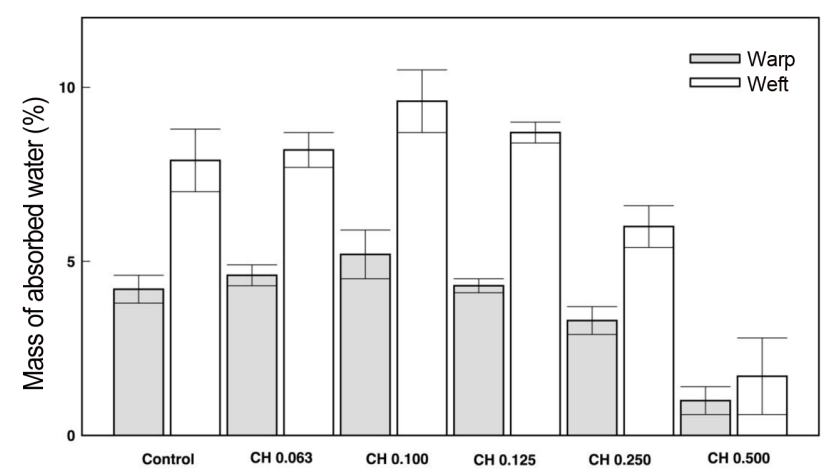

Figure 8. Mass of absorbed water (\%) in warp (grey bars) and weft (white bars) directions of the chitosan coated gauzes. Data represent mean values \pm S.D. $(n=5)$. 
resulting in water diffusing very rapidly through the coated gaze [61]. Higher chitosan concentrations did not give off the absorbed water and limits the water access to the cellulose fibres of cotton gaze. This limits the ability of the dressing to preserve water that is one of the most important issues in wound healing. Effective wound dressings must be able to maintain a prolonged moist microenvironment to improve the epithelialization of wound while preventing the formation of the scab [62].

Cotton gauzes up to $0.100 \mathrm{wt} \%$ of coated chitosan show an increase in water uptake compared to control gauze. The water uptakes of the cotton gauze with $0.125 \mathrm{wt} \%$ show very similar values to the control gauze. Further increase in chitosan concentration ( 0.25 and $0.5 \mathrm{wt} \%$ ) leads to significant lower values of water uptake (Figure 8). Observed water uptake in weft direction is the double than that in warp direction for all tested samples. The gaze coated with $0.5 \mathrm{wt} \%$ of chitosan shows an impressive decrease in water uptake of about $77 \%$ in warp direction and $78 \%$ in weft direction. These results clearly showed that the water absorption capacity of the gauzes, and consequently, their ability to remove exudate from the wound could be tailored by tuning chitosan content.

\section{Antimicrobial Properties}

The best performing chitosan-coated gauze in terms of thermo-physiological comfort properties was further tested for its antimicrobial properties in accordance with Japanese Standard JIS L 1902:2002. Gram-negative (E. coli) and Gram-positive ( $S$. aureus) bacteria, as well as fungi $(C$. albicans) were tested and the results presented in Table 3. Typically, an antimicrobial agent may possess either bacteriostatic or bactericidal properties. Bacteriostatic activity means that it prevents the multiplication of bacteria without destroying them while bactericidal implies the forthright killing of the organisms. As the growth value $(\mathrm{F})$ obtained from the number of living microorganisms, after being in contact with $0.125 \mathrm{wt} \%$ chitosan-impregnated cotton gauze, is always higher than 1.5 the tests were judged to be effective. According to the standard, a value of bactericidal activity (L) higher than zero is an indication of bactericidal activity, while bacteriostatic properties begin with (S) values exceeding 2 . The results has shown that medical gauze when coated with chitosan reveals significant

Table 3. Antimicrobial activity of surgical cotton gauze coated with $0.125 \mathrm{wt} \%$ of chitosan

\begin{tabular}{lccc}
\hline \multirow{2}{*}{ Activity value } & \multicolumn{3}{c}{ Microorganism } \\
\cline { 2 - 4 } & E. coli & S. aureus & C. albicans \\
\hline Microbiostatic activity value (S) & $4.4 \pm 2.2$ & $3.0 \pm 0.3$ & $3.3 \pm 0.2$ \\
Microbiocidal activity value (L) & $2.2 \pm 1.5$ & $1.7 \pm 2.1$ & $0.0 \pm 0.0$ \\
Growth value (F) & $1.8 \pm 0.7$ & $2.3 \pm 0.8$ & $5.0 \pm 0.5$ \\
\hline
\end{tabular}

bactericidal and bacteriostatic activity against both bacteria $(\mathrm{S}>2$ and $\mathrm{L}>0$ ) but showed only a fungistatic activity ( $\mathrm{S}>2$ and $\mathrm{L}=0$ ) against the fungi $C$. albicans.

The significant bactericidal activity against both bacteria is a quite interesting result because of the used low concentration of chitosan. Similar results have only been obtained when chitosan was carboxymethylated [63] or when it was combined with other bactericidal agents such as zinc oxide [64] or silver nanoparticles [65]. This might be due to the fact that higher concentrations of chitosan are usually assumed to be needed for obtaining an antimicrobial textile owed to its reported high values of minimum inhibitory concentration (above $2 \mathrm{mg} / \mathrm{ml}$ in solution) [66]. The electrostatic interactions between the protonated amino groups of chitosan $-\mathrm{NH}_{3}{ }^{+}$and the negatively charged microbial cell membranes are known to be essential for its antimicrobial and antifungal properties [67]. At lower concentrations $(<0.2 \mathrm{mg} / \mathrm{m} l)$, the polycationic chitosan binds to the negatively charged bacterial surface to cause agglutination, while at higher concentrations, the larger number of positive charges impart a net positive charge to the bacterial surfaces to keep them in suspension. Another hypothesis is that chitosan interacts with the membrane of the cell to alter cell permeability, which leads to its disruption and subsequently leakage of proteinaceous and other intracellular constituents [20]. Nevertheless, the actual mechanism has not yet been fully elucidated. In this work, it may be assumed that the chosen concentration favours the mobility of the chitosan macromolecules and their interaction with the membrane of bacteria impeding the occurrence of a steric hindrance effect between chitosan and bacteria. Regarding fungistatic activity, the results are in good agreement with the literature, which report that chitosan possess fungistatic rather than fungicidal properties [67]. Similarly to the effects observed in bacteria cells, chitosan interferes directly with fungal growth by inhibiting cell wall morphogenesis [68]. The suggested mechanism involved a permeable chitosan film formed on the crop surface which interfered with the fungal growth and activated several defence processes like chitinase accumulation, proteinase inhibitor synthesis, callus synthesis and lignification [69].

\section{Conclusion}

In this work, chitosan-coated cotton gauze with antimicrobial properties has been developed with concomitant evaluation of the best thermo-physiological comfort properties, providing an added value material for wound healing purposes able to reduce pain and discomfort to the patient. Different concentrations of chitosan have been impregnated onto cotton gauze and the best performing material in terms of comfort was assessed. An exhaustive characterization of the different functionalized cotton including the moisture control and dressing comfort properties was carried out, which 
allowed concluding that through the application of $0.125 \mathrm{wt} \%$ of chitosan onto cotton gauze, a material with enhanced flexibility, thermal properties, water and air permeability, moist management and low adherence properties was obtained. Despite the used low concentration of chitosan the functionalized cotton gauze further presented bactericidal activity against $S$. aureus and $E$. coli, and fungistatic activity towards the fungi $C$. albicans. This dressing configuration shows high potential in wound healing applications preventing wound microbial contamination and providing the proper healing environment at the same time promoting conformability to the wound area and comfort to the patient.

\section{Acknowledgements}

AZ acknowledges funding from FCT - Fundação para a Ciência e a Tecnologia within the scope of the project POCI01-0145-FEDER-007136 and UID/CTM/00264. A. Zille also acknowledges financial support of the FCT through an Investigator FCT Research contract (IF/00071/2015). JS acknowledge CAPES Foundation, Ministry of Education of Brazil, Proc. no 8976/13-9 and the Department of Textile Engineering of the University of Minho, Portugal. The work regarding the biological analysis was supported by the Programa Operacional, Fatores de competitividade - COMPETE and by national funds through FCT on the scope of the projects PTDC/SAU-MIC/119069/2010, RECI/EBB-EBI/ 0179/2012 and PEst-OE/EQB/LA0023/2013. PT acknowledges SFRH/BPD/86732/2012 grant. The authors thank the Project BioHealth - Biotechnology and Bioengineering approaches to improve health quality, Ref. NORTE-07-0124-FEDER000027, co-funded by the Programa Operacional Regional do Norte (ON.2 - O Novo Norte), QREN, FEDER.

Electronic Supplementary Material (ESM) The online version of this article (doi: 10.1007/s12221-019-9053-2) contains supplementary material, which is available to authorized users.

\section{References}

1. G. S. Lazarus, D. M. Cooper, D. R. Knighton, D. J. Margolis, R. E. Pecoraro, G. Rodeheaver, and M. C. Robson, Arch. Dermatol., 130, 489 (1994).

2. D. Church, S. Elsayed, O. Reid, B. Winston, and R. Lindsay, Clin. Microbiol. Rev., 19, 403 (2006).

3. P. G. Bowler, B. I. Duerden, and D. G. Armstrong, Clin. Microbiol. Rev., 14, 244 (2001).

4. P. N. Malani, S. A. McNeil, S. F. Bradley, and C. A. Kauffman, Clin. Infect. Dis., 35, 1316 (2002).

5. E. R. M. Sydnor and T. M. Perl, Clin. Microbiol. Rev., 24, 141 (2011).

6. C. K. Field and M. D. Kerstein, Am. J. Surg., 167 (1994).

7. R. Wiechula, Int. J. Nurs. Pract., 9, S9 (2003).
8. D. Okan, K. Woo, E. A. Ayello, and G. Sibbald, Adv. Skin Wound Care, 20, 39 (2007).

9. S. M. McCarty and S. L. Percival, Adv. Wound Care, 2, 438 (2013).

10. A. Sood, M. S. Granick, and N. L. Tomaselli, Adv. Wound Care, 3, 511 (2014).

11. T. Wang, X. K. Zhu, X. T. Xue, and D. Y. Wu, Carbohydr. Polym., 88, 75 (2012).

12. H. F. Selig, D. B. Lumenta, M. Giretzlehner, M. G. Jeschke, D. Upton, and L. P. Kamolz, Burns, 38, 960 (2012).

13. A. Francesko, M. M. Fernandes, G. Rocasalbas, S. Gautier, and T. Tzanov in "Advanced Polymers in Medicine" (F. Puoci Ed.), p.401, Springer International Publishing, 2015.

14. D. Archana, B. K. Singh, J. Dutta, and P. K. Dutta, Carbohydr. Polym., 95, 530 (2013).

15. D. Archana, B. K. Singh, J. Dutta, and P. K. Dutta, Int. J. Biol. Macromol., 73, 49 (2015).

16. S. Dhivya, V. V. Padma, and E. Santhini, Biomed., 5, 22 (2015).

17. W. J. Ennis, W. Valdes, M. Gainer, and P. Meneses, $A d v$. Skin Wound Care, 19, 437 (2006).

18. X. Cheng, K. Ma, R. Li, X. Ren, and T. S. Huang, Appl. Surf. Sci., 309, 138 (2014).

19. F. Dinah and A. Adhikari, Ann. Royal Coll. Surg. Engl., 88, 33 (2006).

20. K. Azuma, R. Izumi, T. Osaki, S. Ifuku, M. Morimoto, H. Saimoto, S. Minami, and Y. Okamoto, J. Funct. Biomater, 6, 104 (2015).

21. V. Patrulea, V. Ostafe, G. Borchard, and O. Jordan, Eur. J. Pharm. Biopharm., 97, 417 (2015).

22. H. Ueno, T. Mori, and T. Fujinaga, Adv. Drug Delivery. Rev., 52, 105 (2001).

23. D. Alonso, M. Gimeno, R. Olayo, H. Vazquez-Torres, J. D. Sepulveda-Sanchez, and K. Shirai, Carbohydr. Polym., 77, 536 (2009).

24. X. D. Liu, N. Nishi, S. Tokura, and N. Sakairi, Carbohydr. Polym., 44, 233 (2001).

25. A. El.Shafei and A. Abou-Okeil, Carbohydr. Polym., 83, 920 (2011).

26. M. Gouda and S. M. A. S. Keshk, Carbohydr. Polym., 80, 504 (2010).

27. L. F. Zemljic, O. Sauperl, T. Kreze, and S. Strnad, Text. Res. J., 83, 185 (2013).

28. K. F. El-Tahlawy, M. A. El-Bendary, A. G. Elhendawy, and S. M. Hudson, Carbohydr. Polym., 60, 421 (2005).

29. M. M. G. Fouda, A. El Shafei, S. Sharaf, and A. Hebeish, Carbohydr. Polym., 77, 651 (2009).

30. J. Souza, J. Matos, M. Fernandes, A. Zille, and R. Fangueiro, Procedia Eng., 200, 135 (2017).

31. C. Chung, M. Lee, and E. K. Choe, Carbohydr. Polym., 58, 417 (2004).

32. V. Goodarzi, S. H. Jafari, H. A. Khonakdar, B. Ghalei, and M. Mortazavi, J. Membr. Sci., 445, 76 (2013). 
33. E. Yan, S. Fan, X. Li, C. Wang, Z. Sun, L. Ni, and D. Zhang, Mater. Sci. Eng., C, 33, 461 (2013).

34. P. Monllor, M. A. Bonet, and F. Cases, Eur. Polym. J., 43, 2481 (2007).

35. W. W. Thein-Han, J. Saikhun, C. Pholpramoo, R. D. K. Misra, and Y. Kitiyanant, Acta Biomater., 5, 3453 (2009).

36. F. Fan, W. Zhang, and C. Wang, Cellulose, 22, 1427 (2015).

37. R. Jayakumar, M. Prabaharan, P. T. Sudheesh Kumar, S. V. Nair, and H. Tamura, Biotechnol. Adv., 29, 322 (2011).

38. J. Peiffer, K. Kim, and M. Takatera, Text. Res. J., 87, 424 (2017).

39. L. Naujokaityte, E. Strazdiene, and L. Fridrichova, Tekstil, 56, 343 (2007).

40. U. Wollina, M. B. Abdel-Naser, and S. Verma, Curr. Probl. Dermatol., 33, 1 (2006).

41. M. Akgun, Fiber. Polym., 14, 1372 (2013).

42. S. Mandal, G. Song, M. Ackerman, S. Paskaluk, and F. Gholamreza, Text. Res. J., 83, 1005 (2012).

43. S. Gunesoglu, Indian J. Fibre Text. Res., 31, 415 (2006).

44. I. Salopek Čubrić, Z. Skenderi, A. Mihelić-Bogdanić, and M. Andrassy, Exp. Therm Fluid Sci., 38, 223 (2012).

45. S. Alay, C. Alkan, and F. Göde, J. Text. Inst., 103, 757 (2012).

46. E. Onofrei, A. M. Rocha, and A. Catarino, J. Eng. Fibers Fabr, 6, 10 (2011).

47. S. B. Stanković, D. Popović, and G. B. Poparić, Polym. Test., 27, 41 (2008).

48. P. Kanakaraj and R. Ramachandran, JTATM, 9, 1 (2015).

49. S. S. Ramkumar, A. Purushothaman, K. D. Hake, and D. D. McAlister, J. Eng. Fibers Fabr., 2, 10 (2007).

50. G. Schultz, D. Mozingo, M. Romanelli, and K. Claxton, Wound Repair. Regen., 13, S1 (2005).

51. U. Wollina, M. Heide, W. Müller-Litz, D. Obenauf, and J. Ash, Curr. Probl. Dermatol., 31, 82 (2003).

52. R. T. Ogulata and S. Mavruz, Fibres Text. East. Eur., 18, 71 (2010).

53. B. Wilbik-Halgas, R. Danych, B. Wiecek, and K. Kowalski, Fibres Text. East. Eur., 14, 77 (2006).

54. F. Wang, S. del Ferraro, L.-Y. Lin, T. Sotto Mayor, V.
Molinaro, M. Ribeiro, C. Gao, K. Kuklane, and I. Holmér, Ergonomics, 55, 799 (2012).

55. I. Carvalho, M. Henriques, J. C. Oliveira, C. F. Almeida Alves, A. P. Piedade, and S. Carvalho, Sci. Technol. Adv. Mater., 14, 035009 (2016).

56. T. Rakmanee, I. Olsen, G. S. Griffiths, and N. Donos, Analyst, 135, 182 (2010).

57. M. Manshahia and A. Das, Indian J. Fibre Text. Res., 39, 441 (2014).

58. M. A. Fonder, G. S. Lazarus, D. A. Cowan, B. AronsonCook, A. R. Kohli, and A. J. Mamelak, J. Am. Acad. Dermatol., 58, 185 (2008).

59. J. S. Boateng, K. H. Matthews, H. N. E. Stevens, and G. M. Eccleston, J. Pharm. Sci., 97, 2892 (2008).

60. A. Nazir, T. Hussain, G. Abbas, and A. Ahmed, J. Nat. Fibers, 12, 232 (2015).

61. F. Xu, B. Weng, R. Gilkerson, L. A. Materon, and K. Lozano, Carbohydr. Polym., 115, 16 (2015).

62. H. Li, J. Yang, X. Hu, J. Liang, Y. Fan, and X. Zhang, J. Biomed. Mater. Res., A, 98A, 31 (2011).

63. B. Venkatraja, V. V. Malathy, B. Elayarajah, R. Rajendran, and R. Rammohan, Pak. J. Biol. Sci., 16, 1438 (2013).

64. P. Petkova, A. Francesko, M. M. Fernandes, E. Mendoza, I. Perelshtein, A. Gedanken, and T. Tzanov, ACS Appl. Mater. Interfaces, 6, 1164 (2014).

65. M. Abbasipour, M. Mirjalili, R. Khajavi, and M. M. Majidi, J. Eng. Fibers Fabr., 9, 124 (2014).

66. M. M. Fernandes, A. Francesko, J. Torrent-Burgués, and T. Tzanov, React. Funct. Polym., 73, 1384 (2013).

67. D. Raafat, K. von Bargen, A. Haas, and H. G. Sahl, Appl. Environ. Microbiol., 74, 7455 (2008).

68. V. E. Tikhonov, E. A. Stepnova, V. G. Babak, I. A. Yamskov, J. Palma-Guerrero, H.-B. Jansson, L. V. LopezLlorca, J. Salinas, D. V. Gerasimenko, I. D. Avdienko, and V. P. Varlamov, Carbohydr. Polym., 64, 66 (2006).

69. R. Cheung, T. Ng, J. Wong, and W. Chan, Mar. Drugs, 13, 5156 (2015).

70. E. Pinho, G. Soares, M. Henriques, and M. Grootveld, AATCC J. Res., 2, 1 (2015). 